City University of New York (CUNY) CUNY Academic Works

2012

\title{
Thermal analysis of organically modified siloxane melting gels
}

Andrei Jitianu

CUNY Lehman College

Kristin Lammers

Georgia A. Arbuckle-Kiel

Lisa C. Klein

\section{How does access to this work benefit you? Let us know!}

More information about this work at: https://academicworks.cuny.edu/le_pubs/67

Discover additional works at: https://academicworks.cuny.edu

This work is made publicly available by the City University of New York (CUNY).

Contact: AcademicWorks@cuny.edu 


\title{
Thermal analysis of organically modified siloxane melting gels
}

\author{
Andrei Jitianu $\cdot$ Kristin Lammers • \\ Georgia A. Arbuckle-Kiel • Lisa C. Klein
}

Received: 18 March 2011/Accepted: 21 October 2011/Published online: 16 November 2011

(C) Akadémiai Kiadó, Budapest, Hungary 2011

\begin{abstract}
Hybrid melting gels were prepared by a sol-gel process, starting with a mono-substituted siloxane and a disubstituted siloxane, methyltrimethoxysilane (MTES) together with dimethyldimethoxysilane (DMDES). Five gel compositions were prepared with concentrations between 50\% MTES-50\% DMDES and 75\% MTES-25\% DMDES (in mol.\%). The consolidation temperature, the treatment temperature after which the melting gel no longer softens, increased from 135 to $160{ }^{\circ} \mathrm{C}$ with a decrease in the amount of the mono-substituted siloxane. The glass transition temperature, recorded with differential scanning calorimetry, decreased from -0.3 to $-56.7{ }^{\circ} \mathrm{C}$ with a decrease in the amount of the mono-substituted siloxane. When a sample was heat treated isothermally for $2 \mathrm{~h}$ at the consolidation temperature, the glass transition temperature increased by about $15^{\circ}$, indicating further crosslinking of the siloxane network.
\end{abstract}

\footnotetext{
A. Jitianu

Department of Chemistry, Lehman College, City University of New York, Davis Hall, 250 Bedford Park Boulevard West, Bronx, NY, USA 10468
}

\section{A. Jitianu · L. C. Klein $(\bowtie)$ \\ Department of Materials Science and Engineering, Rutgers University, 607 Taylor Road, Piscataway, NJ 08854, USA e-mail: licklein@ rci.rutgers.edu}

K. Lammers · G. A. Arbuckle-Kiel

Department of Chemistry, Rutgers University, Camden, NJ 08102, USA

K. Lammers

Department of Chemistry, Temple University, Philadelphia, PA 19122, USA

\section{Introduction}

Silica-based organic-inorganic hybrid nanocomposites can be formed with a stable inorganic framework combined with a variety of organo-functional groups [1]. The physical and chemical properties of the nanocomposites differ from the properties predicted by simple mixing rules [2]. Schmidt [3] identified one type of nanocomposites, where the organic modifiers are stable toward chemical reaction (e.g., methyl or phenyl). When hydrolytically stable groups are used, it is found in some cases that the gels exhibit the behavior of so-called melting gels.

Melting gels are a class of organically modified silica gels that are rigid at room temperature, flow at temperature $T_{1}$ and consolidate at temperature $T_{2}\left(T_{2}>T_{1}\right)$, when crosslinking is complete. The process of (a) softening, (b) becoming rigid, and (c) re-softening can be repeated many times. So-called melting gels were developed originally to replace low melting inorganic glasses. Matsuda et al. [4] reported the softening behavior of melting gels, prepared with poly(benzylsilsesquioxane) particles. Subsequently, using phenyl triethoxysilane (PhTES) with diphenyl diethoxysilane (DPhDES) or methyl triethoxysilane (MTES) with dimethyl diethoxysiliane (DMDES), Masai et al. [5] obtained organically modified polysilsesquioxanes with low softening points. They used hydrochloric acid first to hydrolyze the mixture, followed by ammonia for condensation. ${ }^{29} \mathrm{Si}-\mathrm{NMR}$ and gel permeation chromatography were used to study the complex structure of the gels in the PhTESDPhDES and (PhTES) $)_{1}(\mathrm{MTES})_{(1-x)}$-DPhDES systems [6, 7], which showed that the molecular structures of the gels were three dimensional, with the organic groups having weak bonds between molecular chains.

As a general trend, the organic moieties bonded or embedded in inorganic matrices have higher thermal 
stability than the same individual organic components. De Witte et al. [8] studied the formation of organo-modified silicates using tetraethyl orthosilane (TEOS) with MTES and dimethyl dimethoxysilane (DMDMS). They investigated the distribution of methyl groups in the gels. They showed that they could determine the distribution of the methyl groups, based on the analysis of the exothermic peaks from differential thermal analysis (DTA) in air. Generally, they concluded that a broad exothermic peak indicated a uniform distribution of the methyl groups throughout the entire gel network, while a narrow peak indicated a preference of the methyl groups for the surface of the gels.

The thermal stability of hybrid nanocomposites obtained by co-condensation of polyamideimide-epoxysilane together with oligomeric polydimethylsiloxane was studied as a function of the amount of polyamideimide-epoxysilane [9]. From the mass loss measurements both in nitrogen and in air it was shown that the thermal stability of the polyamideimide-epoxysilane increased with an increase in the polydimethylsiloxane concentration. Yu et al. [10-12] studied dielectric properties as a function of temperature in hybrid mesoporous silica obtained using TEOS and MTES. They observed that the dielectric constant of the hybrid is higher than silica until $300{ }^{\circ} \mathrm{C}$ due to the organic content. Above this temperature, the dielectric constant decreases when the methyl groups decompose. The DTA curve showed a maximum at $400{ }^{\circ} \mathrm{C}$, assigned to the oxidative pyrolysis of the $\mathrm{CH}_{3}$ groups. Rao et al. [13, 14] showed that for silica aerogels prepared with methyl trimethoxysilane (MTMS) the pyrolysis of the methyl groups takes place at $480{ }^{\circ} \mathrm{C}$, while the pyrolysis of the methyl groups in aerogels prepared with MTES takes place at $540{ }^{\circ} \mathrm{C}$.

There are several methods to obtain silicon oxycarbide glasses by thermal decomposition in an inert atmosphere with gels obtained from MTES, vinyl triethoxysilane (VTES), PhTES [15] and mixtures of TEOS with DMDES [16]. By using DMDES, VTES and PhTES, the molar ratio $\mathrm{Si} / \mathrm{C}$ can be adjusted. Gels obtained with TEOS and DMDES are thermally stable in inert atmosphere up to $700{ }^{\circ} \mathrm{C}$, while the same gels start to decompose in air at around $350{ }^{\circ} \mathrm{C}$ [16].

Generally, when DMDES undergoes hydrolysis and polycondensation, polydimethylsiloxanes (PDMS) are obtained. Camino et al. [17, 18] have investigated the thermal degradation of PDMS using in situ FT-IR and evolved gas analysis. The degradation takes place in two steps. First, oligomers are volatilized at lower temperatures. Then they oxidize through a peroxidation mechanism, initiated by radicals that produce hydroperoxide, which is further decomposed to produce hydrogen. When hybrid materials obtained from TEOS and MTES are decomposed in air, a radical mechanism is proposed, which leads to formation of hydrogen and methane, as well as further crosslinking of $\mathrm{Si}-\mathrm{O}-\mathrm{Si}$ chains, at temperatures between 400 and $450{ }^{\circ} \mathrm{C}$ [19].

For membranes prepared using MTMS and DPhDES [20], thermal analysis indicated that the methyl groups were eliminated at $\sim 380{ }^{\circ} \mathrm{C}$, while the phenyl groups were pyrolyzed at $\sim 550{ }^{\circ} \mathrm{C}$. When membranes obtained using MTMS were used to remove vapors from waste gasses, it was shown that the membranes were stable until $350{ }^{\circ} \mathrm{C}$ when the methyl groups were removed and the membrane become hydrophilic [21]. Zhou et al. [22] studied the thermal stability of branched and linear polysiloxanes obtained in the MTES-PhTES system. They concluded that branched polysiloxanes were more stable than linear ones. This was attributed to the fact that crosslinking reduces flexibility and inhibits pyrolysis.

Differential scanning calorimetry (DSC) has been used to identify the glass transition temperature in organically modified siloxanes. The glass transition is generally thought of as the interval of transition between liquid and glassy states. The glass transition is associated with a temperature $T_{\mathrm{g}}$, which is influenced by a number of macroscopic properties, such as viscosity, dielectric constant, and mechanical properties. Using the approach developed for traditional organic polymers and applied to inorganic silica-based polymers [23], the glass transition temperature is a reflection of the degree of cross-linking in the silica network. The $T_{\mathrm{g}}$ should increase with an increase in the number of oxygen bridges between silicon atoms. In one system using functional polysiloxanes, it was found that the $T_{\mathrm{g}}$ decreased with an increase of the organofunctional comonomer [24, 25].

Another subclass of hybrid gels is epoxy resins modified with siloxanes. Generally, the $T_{\mathrm{g}}$ is an indication of the thermal stability of the epoxy resins. For epoxy resins modified with siloxanes such as DMDES, the $T_{\mathrm{g}}$ can change because of self-condensation of the DMDES, leading to an increase in the length of organosiloxane chains [26].

This article is focused on the thermal stability of melting gels in the MTES-DMDES system. Originally, the melting gels were investigated for hermetic barriers for protection from humidity and atmospheric gasses for electronic devices [27]. The temperature of consolidation of these hybrid glasses had to be below the temperature of degradation for silicon microelectronics [28]. The processing temperatures for the melting gels in the MTES-DMDES were reported [29]. The general trend was that the consolidation temperatures decreased with a decrease of the amount of di-substituted siloxane, while the glass transition temperatures showed the opposite trend, an increase of $T_{\mathrm{g}}$ with a decrease of the amount of di-substituted siloxane [30]. To get a better understanding of the behavior of melting gels, a full thermal analysis, involving DTA, thermal gravimetry and DSC has been carried out. 


\section{Experimental}

Gel preparation

The preparation of the melting gels has been reported elsewhere [27, 29]. Melting gels were prepared using mono-substituted and di-substituted alkoxysilanes. Methyltriethoxysilane (MTES) (Sigma-Aldrich, Milwaukee, WI) as mono-substituted precursor and dimethyldiethoxysilane (DMDES) (Fluka Chemicals, Milwaukee, WI) as di-substituted precursor were used. All reagents were used without further purification. Hydrochloric acid (Fisher Scientific, Atlanta, GA) and ammonium hydroxide (SigmaAldrich, Milwaukee, WI) were used as catalysts. Anhydrous ethanol (Sigma-Aldrich, Milwaukee, WI) was used as solvent. The compositions of the melting gels are indicated in mol \% of mono-substituted and di-substituted alkoxides and are listed in Table 1.

The synthesis was performed in three steps. First an aqueous solution was prepared by mixing water with hydrochloric acid and with half of the ethanol. Separately, the MTES was mixed with the other half of the ethanol. Then, the ethanol mixed with MTES was added dropwise to the aqueous acid solution under continuous stirring. The container was covered tightly to prevent solvent evaporation, and the mixture was stirred at room temperature for $3 \mathrm{~h}$. The molar ratios of MTES:MeOH: $\mathrm{H}_{2} \mathrm{O}: \mathrm{HCl}$ were 1:4:3:0.01.

In the second step, the di-substituted alkoxysilane DMDES was diluted with ethanol in a molar ratio of DMDMS:MeOH = 1:4. The DMDES-EtOH mixture was added dropwise to the first mixture. This resulting solution was kept under continuous stirring in a closed container at room temperature for two additional hours.

In the third step, ammonium hydroxide was added to the reaction mixture, which was stirred for one hour in a closed container. The molar ratio of (MTES + DMDES): $\mathrm{NH}_{4} \mathrm{OH}$ was 1:0.01. This final solution was stirred for $48 \mathrm{~h}$ at room temperature in an open container until gelation occurred. During the gelation it was observed that a white powder of ammonium chloride formed. To remove the ammonium

Table 1 Glass transition $\left(T_{\mathrm{g}}\right)$, consolidation temperature $\left(T_{\mathrm{CON}}\right)$ and total mass loss

\begin{tabular}{|c|c|c|c|c|c|}
\hline \multirow{2}{*}{$\begin{array}{l}\text { MTES/ } \\
\text { mol. } \%\end{array}$} & \multirow{2}{*}{$\begin{array}{l}\text { DMDES/ } \\
\text { mol. } \%\end{array}$} & \multicolumn{2}{|l|}{$T_{\mathrm{g}} /{ }^{\circ} \mathrm{C}$} & \multirow[t]{2}{*}{$T_{\mathrm{CON}} /{ }^{\circ} \mathrm{C}$} & \multirow{2}{*}{$\begin{array}{l}\text { Total mass } \\
\text { loss } / \%\end{array}$} \\
\hline & & Before & After & & \\
\hline 50 & 50 & -56.7 & - & 160 & 45 \\
\hline 60 & 40 & -37.7 & - & 155 & 37 \\
\hline 65 & 35 & -18.8 & 3.1 & 150 & 35 \\
\hline 70 & 30 & -6.4 & 9.4 & 145 & 34 \\
\hline 75 & 25 & -0.3 & 17.3 & 135 & 30 \\
\hline
\end{tabular}

chloride, $10 \mathrm{~mL}$ of dry acetone (Spectranal, Riedel-de Haën) was added to the samples. The ammonium chloride was separated from the gels by vacuum filtration. The clear product was stirred in an open container, followed by a heat treatment at $70{ }^{\circ} \mathrm{C}$ for $24 \mathrm{~h}$ to remove any remaining acetone and ethanol, followed by another heat treatment at $110{ }^{\circ} \mathrm{C}$ for removal of any remaining water.

It was observed that after these heat treatments, the gels were rigid at room temperature. However, when heated to $\sim 110{ }^{\circ} \mathrm{C}$, the gels softened and became fluid. The consolidation temperature was established empirically by going through heating and cooling cycles until a temperature was reached after which the gels could not be softened. Once the gel had been heated to the consolidation temperature, the behavior was no longer reversible. The consolidation temperatures are listed in Table 1.

\section{Materials characterization}

The thermal stability of the fresh gels before their consolidation was studied using differential thermal analysis (Perkin-Elmer DTA-7), thermogravimetric analysis (Perkin-Elmer TGA-7) and differential scanning calorimetry (DSC TA-Q-2000). DTA and TG were recorded at $5{ }^{\circ} \mathrm{C} / \mathrm{min}$ heating rate in the temperature range between 50 and $800{ }^{\circ} \mathrm{C}$ under air flow $(20 \mathrm{~mL} / \mathrm{min})$. The thermal analysis in the inert atmosphere (TA Instruments 2050 TGA) was performed in the temperature range between 50 and $800{ }^{\circ} \mathrm{C}$ with a heating rate of $5{ }^{\circ} \mathrm{C} / \mathrm{min}$ under nitrogen flow $(20 \mathrm{~mL} / \mathrm{min})$. The DSC analyses were recorded using a $5{ }^{\circ} \mathrm{C} / \mathrm{min}$ heating rate between -70 and $400{ }^{\circ} \mathrm{C}$ in nitrogen flow $(20 \mathrm{~mL} / \mathrm{min})$.

The DSC isothermal experiments where performed as follows. The samples were heated at $5{ }^{\circ} \mathrm{C} / \mathrm{min}$ from room temperature up to $5^{\circ} \mathrm{C}$ above the consolidation temperature for the particular sample. At this temperature, the sample was held isothermally for $2 \mathrm{~h}$, followed by cooling to $-40^{\circ} \mathrm{C}$. Then the DSC analysis was performed again in a dynamic mode from $-40{ }^{\circ} \mathrm{C}$ up to $400{ }^{\circ} \mathrm{C}$ with a heating rate of $5{ }^{\circ} \mathrm{C} / \mathrm{min}$, same as the original heating rate.

For the TGA-FTIR analysis, a TA Instruments 2050 TGA was connected to a Bio-Rad FTS-6000 IR system via a heated transfer line maintained at $250{ }^{\circ} \mathrm{C}$. A heated transmission IR cell (Harrick Scientific HTC 100) was used for in situ transmission infrared studies. The cell was controlled by an automatic temperature feedback controller (AT-30D) and was water cooled to prevent damage to the cell windows $(\mathrm{KBr})$. The cell was continuously purged with nitrogen to maintain an inert atmosphere within the cell.

The TG-FTIR isothermal experiments were conducted as follows. The samples were loaded in the $\mathrm{TG}$ at room temperature. They were heated at a rate of $5{ }^{\circ} \mathrm{C} / \mathrm{min}$ up to $5^{\circ} \mathrm{C}$ above the consolidation temperature. Then the 
samples were maintained at the consolidation temperatures for $2 \mathrm{~h}$. The evolved gasses during heating up to the consolidation temperature and during the isothermal treatment were passed through a heated transfer line maintained at $250{ }^{\circ} \mathrm{C}$ to the IR cell for analysis.

\section{Results}

The results of thermal gravimetric analysis and DTA performed in air are presented in Fig. 1. The \% mass losses for all samples along with their compositions are listed in Table 1.

The thermal analysis was performed on freshly prepared, unconsolidated gels. The $\%$ mass loss increases with increasing amount of di-substituted siloxane (DMDES), reflecting the increasing organic content. For all compositions, two steps of mass loss are recorded on the TG curves. The first step occurs between 150 and $280{ }^{\circ} \mathrm{C}$. This mass loss is associated with removal of residual unreacted alkoxide precursors. This mass loss step corresponds to a small exotherm around $270{ }^{\circ} \mathrm{C}$, which is attributed to oxidation of residual ethoxy groups. The second step occurs between 360 and $490{ }^{\circ} \mathrm{C}$. This mass loss step corresponds to the peak in the exotherm around $440{ }^{\circ} \mathrm{C}$ on the DTA curves. This step is assigned to the pyrolysis of methyl groups. For the 50\% MTES-50\% DMDES sample, the second step starts at a slightly lower temperature $\left(340{ }^{\circ} \mathrm{C}\right)$. This sample has the highest methyl content of all of the samples. None of the samples lose mass below $150{ }^{\circ} \mathrm{C}$ when the samples are decomposed in air.

Figure 2 is the thermal gravimetric analysis in nitrogen of the 75\% MTES-25\% DMDES sample. The thermal decomposition of the sample in nitrogen occurs in four steps.

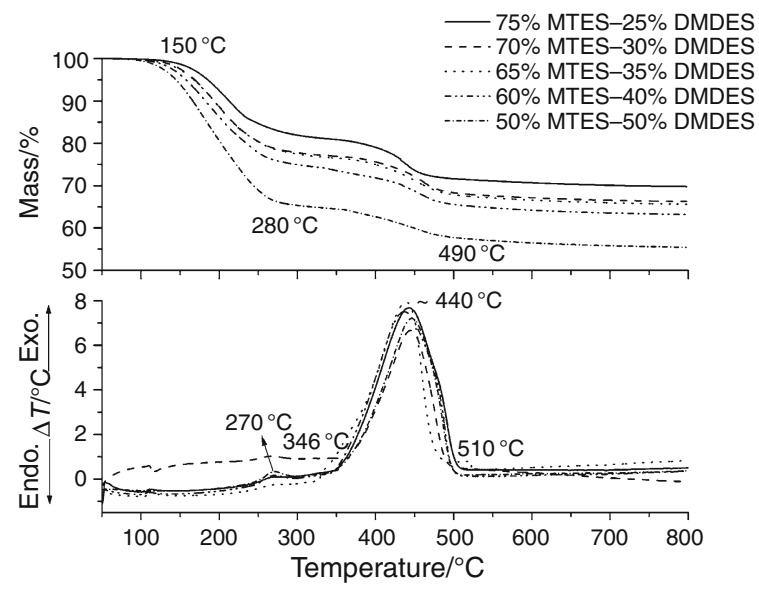

Fig. 1 Thermogravimetric (TG) curves (a) and differential thermal analysis (DTA) curves (b) for fresh melting gels heated in air at $5^{\circ} \mathrm{C} / \mathrm{min}$
The first step occurs between room temperature and $150{ }^{\circ} \mathrm{C}$. This mass loss of about $0.5 \%$ is attributed to the evaporation of remaining organic solvents. The second step is between 150 and $445^{\circ} \mathrm{C}$. This mass loss is attributed to removal of hydroxyl groups and ethoxy groups. During this step, the mass loss is about $45 \%$. In samples heated in air, this mass loss occurs at lower temperatures, between 150 and $280{ }^{\circ} \mathrm{C}$. In nitrogen, the decomposition of methyl groups does not occur until the temperature reaches $445^{\circ} \mathrm{C}$. The final thermal decompositions in nitrogen occur between 445 and $625{ }^{\circ} \mathrm{C}$ and between 625 and $800{ }^{\circ} \mathrm{C}$. The mass loss attributed to methyl decomposition is about $6.7 \%$.

The DSC curves for all samples are shown in Fig. 3. The glass transition temperatures $\left(T_{\mathrm{g}}\right)$ for all compositions are listed in Table 1.

The $T_{\mathrm{g}}$ decreases with an increase in the amount of disubstituted siloxane (DMDES), between -0.3 and $-56{ }^{\circ} \mathrm{C}$. All of the DSC curves show an endotherm around $160^{\circ} \mathrm{C}$, which starts at $\sim 115{ }^{\circ} \mathrm{C}$ and has a maximum at $165^{\circ} \mathrm{C}$. Over this temperature interval, there is little change in mass (Fig. 2). In addition, the curves show an exotherm at $\sim 265^{\circ} \mathrm{C}$. The exotherm corresponds to the mass loss due to decomposition in nitrogen, which takes place between 150 and $445{ }^{\circ} \mathrm{C}$ (Fig. 2). For the samples with higher content of DMDES (40 and 50\%), an additional exotherm occurs at $310^{\circ} \mathrm{C}$. This additional peak is linked to the large amount of organic contained in these samples.

Figure 4 displays the DSC curves for the 75\% MTES$25 \%$ DMDES sample during isothermal consolidation. The behavior of this sample is typical for all samples subjected to isothermal treatment.

To investigate what happens at the consolidation temperature, the sample was held isothermally at a temperature $5{ }^{\circ} \mathrm{C}$ above its consolidation temperature. The consolidation temperature is the beginning of the broad endotherm

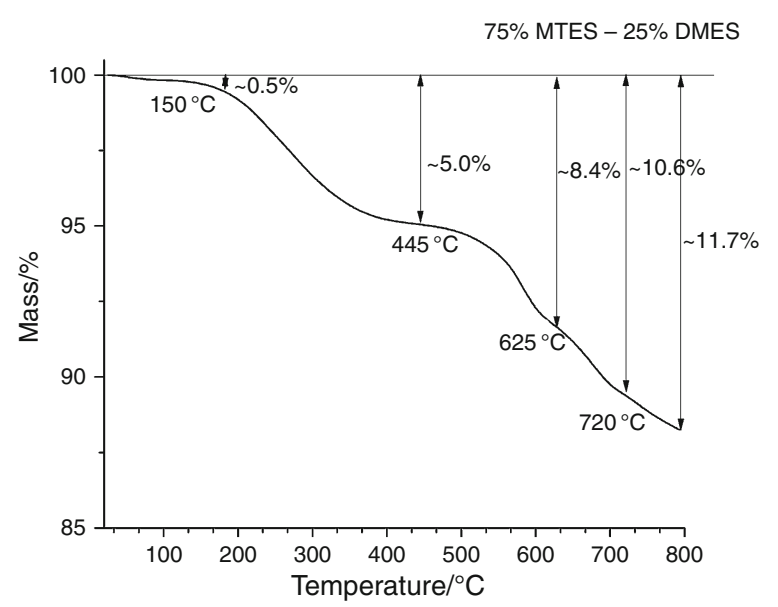

Fig. 2 Thermogravimetric curve for fresh melting gel 75\% MTES$5 \%$ DMDES heated in nitrogen at $5{ }^{\circ} \mathrm{C} / \mathrm{min}$ 


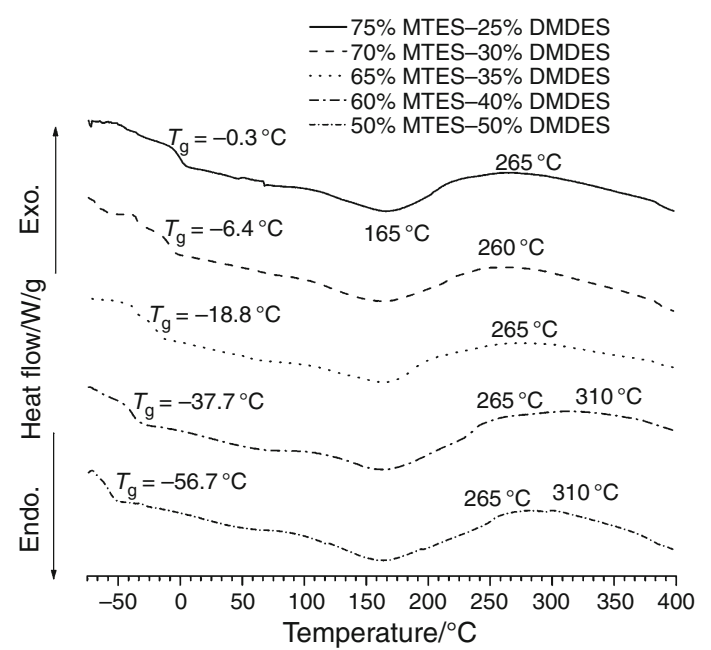

Fig. 3 Differential scanning calorimetry (DSC) curves for fresh melting gels heated in nitrogen at $5{ }^{\circ} \mathrm{C} / \mathrm{min}$

that peaks around $165{ }^{\circ} \mathrm{C}$ (curve a). After $2 \mathrm{~h}$ of isothermal treatment at $140{ }^{\circ} \mathrm{C}$ (curve b), the same sample was heated again from below room temperature (curve c). The endotherm disappeared and the exotherm was less intense. Moreover, the glass transition temperature increased to about $17{ }^{\circ} \mathrm{C}$. The higher $T_{\mathrm{g}}$ temperatures after the isothermal treatment are listed in Table 1 for three compositions. The increase is between $15^{\circ}$ and $22^{\circ}$.

Figure 5a displays the mass loss curve during isothermal treatment in nitrogen and Fig. 5b displays the FT-IR spectra of the evolved gasses, for the sample $75 \%$ MTES25\% DMDES.

The thermal gravimetric analysis shows about 1.8\% mass loss during heat up. Upon reaching the consolidation temperature the samples were held at $140{ }^{\circ} \mathrm{C}$ for $2 \mathrm{~h}$. The

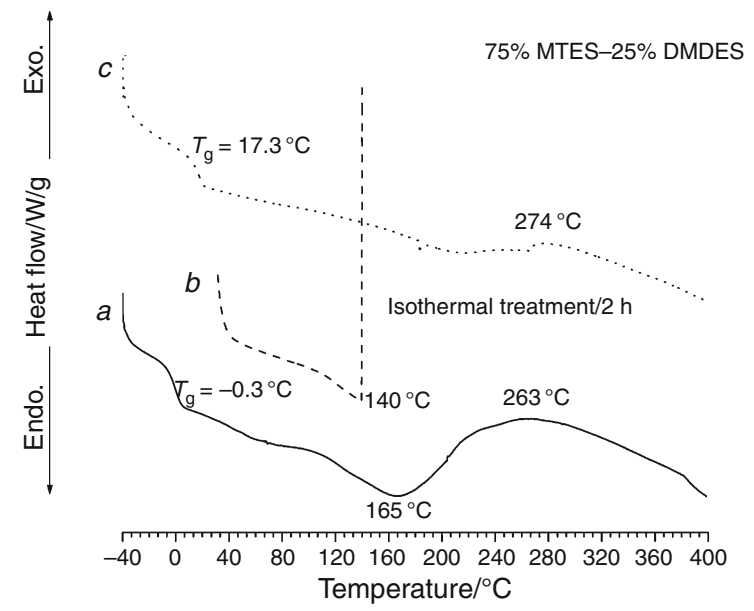

Fig. 4 DSC curves for 75\% MTES-25\% DMDES gels in nitrogen: (a) heated fresh from -40 to $400{ }^{\circ} \mathrm{C}$ at $5{ }^{\circ} \mathrm{C} / \mathrm{min},(b)$ held isothermally for $2 \mathrm{~h}$ at the consolidation temperature $140{ }^{\circ} \mathrm{C},(c)$ reheated from -40 to $400{ }^{\circ} \mathrm{C}$ at $5{ }^{\circ} \mathrm{C} / \mathrm{min}$ after isothermal consolidation mass loss during this isothermal treatment was $\sim 9 \%$. The gasses evolved during this were collected and analyzed. In the FT-IR spectra recorded during the isothermal treatment, the only gas identified in the spectra is $\mathrm{CO}_{2}$. The vibrations in the FT-IR spectra were assigned to $v_{\mathrm{as}} \mathrm{CO}_{2}$ at $2367 \mathrm{~cm}^{-1}$ and $\delta \mathrm{O}=\mathrm{C}=\mathrm{O}$ at $666 \mathrm{~cm}^{-1}$. The intensity of these peaks increases from the beginning of the thermal treatment up to $40 \mathrm{~min}$. After $40 \mathrm{~min}$ of isothermal treatment, the intensity of the peaks decreases. The mass loss curves reach a plateau around the same time. There was no evidence in the spectra for water, ethoxy or other organics.

\section{Discussion}

During heating from 50 to $800{ }^{\circ} \mathrm{C}$, the samples lose mass when methyl groups are removed. The total mass loss increased in samples with higher di-substituted siloxane content. The removal of the methyl groups occurs at a higher temperature in nitrogen than in air. The thermal
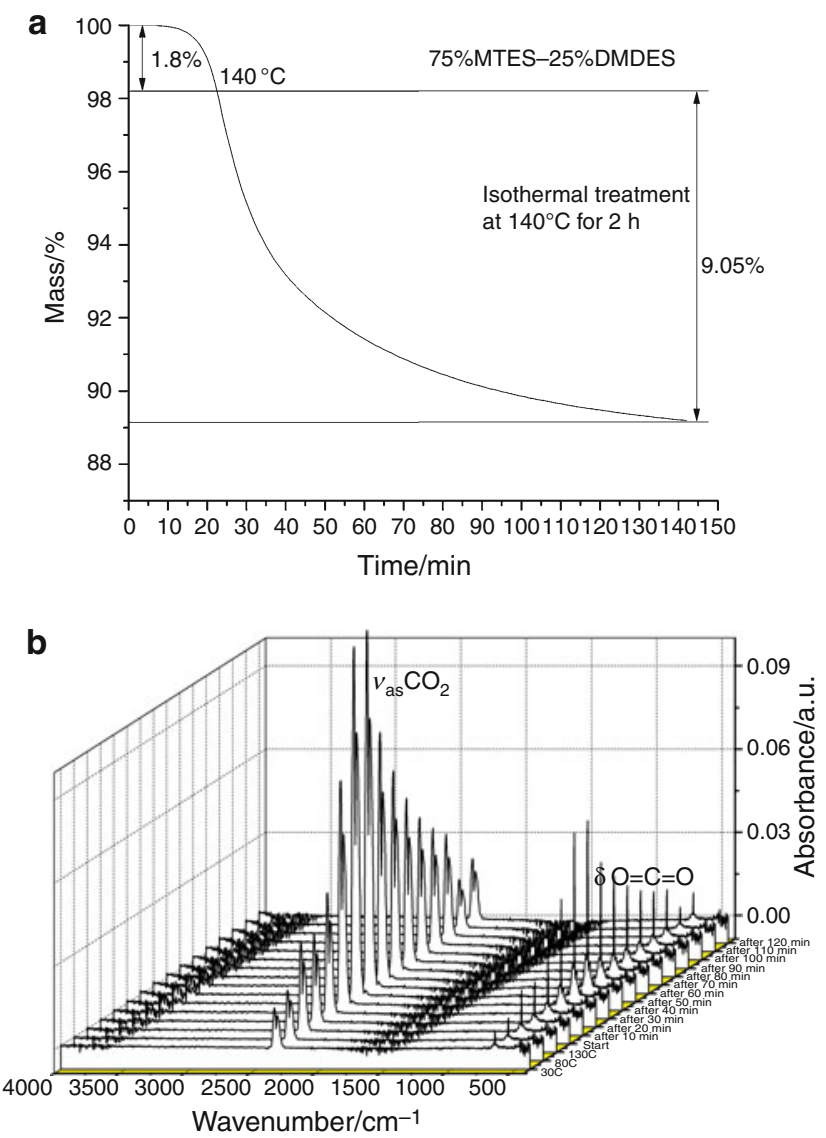

Fig. 5 a Mass loss curve for $75 \%$ MTES-25\% DMDES gel during $2 \mathrm{~h}$ isothermal treatment at $140{ }^{\circ} \mathrm{C}$. b The Fourier transform infrared spectra of evolved gasses collected from sample 75\% MTES-25\% DMDES during the $2 \mathrm{~h}$ isothermal treatment at $140{ }^{\circ} \mathrm{C}$ 
decomposition of 50\% MTES-50\% DMDES in air starts at a lower temperature $\sim 340{ }^{\circ} \mathrm{C}$ than the other compositions. This sample has the highest content of methyl groups. The high organic content can accelerate the thermal decomposition when methyl groups close to the surface are subject to combustion. The thermal analysis curve shows a broad exotherm between 346 and $510{ }^{\circ} \mathrm{C}$, indicating that methyl groups are distributed throughout the sample and are removed over a wide temperature range [8].

The decomposition of the samples in nitrogen is more complicated than in air. Usually, in air the organic groups undergo pyrolysis. In inert atmosphere, decomposition occurs at higher temperatures. First the $\mathrm{Si}-\mathrm{C}$ bond in $\mathrm{Si}-\mathrm{CH}_{3}$ is broken, followed by formation of radical species, which are then desorbed [19]. In nitrogen, the surface methyl groups are removed first, since they are more exposed. Second, the methyl groups are removed from open pores. Decomposition is not complete even at $800{ }^{\circ} \mathrm{C}$, as the mass loss curve has not reached a plateau. The continued mass loss indicates the difficulty of removing all of the methyl groups.

While the methyl groups are decomposing, the silica network is crosslinking further. Shrinkage accompanies the crosslinking, and some of the methyl groups are entrapped in the silica network. Samples heated in nitrogen are black after the thermal analysis, while samples heated in air are white, presumably only $\mathrm{SiO}_{2}$.

The glass transition temperature observed in scanning calorimetry is often associated with polymer chain stiffness, where the polymers are the siloxane chains formed during the sol-gel process. A decrease of the $T_{\mathrm{g}}$ occurs with an increase of the number of non-hydrolytic organic groups, meaning a decrease in the number of oxygen bridges between siloxane chains [19, 24]. Moreover, higher numbers of non-hydrolytic organic groups lead to the formation of more linear polysiloxanes. An increase in the percent of the di-substituted siloxane increases the number of $\mathrm{Si}-\mathrm{CH}_{3}$ bonds, which prevents the crosslinking of the molecular chains into three dimensional networks. A low glass transition temperature in melting gels indicates linear polymeric chains [23]. The $T_{\mathrm{g}}$ of polydimethylsiloxane, which is formed only from the linear polysiloxane chains is $\sim-100{ }^{\circ} \mathrm{C}$ [9].

The isothermal treatments around the consolidation point lead to changes in the structure of the polysiloxanes chains. Following isothermal treatment, the endotherm observed in the original scanning calorimetry is absent during reheating. While holding isothermally at the consolidation temperature, the melting gels, which initially are fluid, have mobile polysiloxane chains that move into positions in such a way that the organically modified silica chains continue to crosslink. At the consolidation temperature, the formation of a three dimensional network proceeds and the gels become irreversible. Normally, crosslinking, which is associated with the formation of new bonds is exothermic. However, crosslinking in melting gels involves the formation of new bonds and the breaking of others bonds such as $\mathrm{Si}-\mathrm{OH}$. The net effect in fresh gels is an endotherm.

The increase of the glass transition temperatures after isothermal treatment at the consolidation temperature reflects additional crosslinking of the silica chains and the formation of a three dimensional network. In siloxanes an increase in the $T_{\mathrm{g}}$ is associated with an increase in the number of the oxygen bridges between the silicon atoms [23].

The infrared spectra collected from evolved gases during isothermal treatment are useful in following the chemical evolution of the gels. Only $\mathrm{CO}_{2}$ was identified in the evolved gasses during the consolidation. The $\mathrm{CO}_{2}$ indicates the decomposition of unreacted organic groups. Note that no water was identified in the evolved gasses.

Finally, Fig. 6 is a summary of the glass transition temperatures measured from scanning calorimetry and the empirically determined consolidation temperatures, as a function of the mono-substituted siloxane content. Along with the MTES-DMDES system, the temperatures for the methyltrimethoxysilane-dimethyldimethoxysilane (MTMS -DMDMS) system are included for comparison [30]. For both systems, the consolidation temperatures decrease with a decrease of the amount of di-substituted alkoxysilanes (DMDES or DMDMS), while the glass transition temperatures show the opposite trend, an increase with a decrease of di-substituted siloxane. An extrapolation of these trends would indicate that the limit of melting gel behavior would occur with too little di-substituted alkoxysilane, when $T_{\mathrm{g}}$ and the consolidation temperature converge. To further

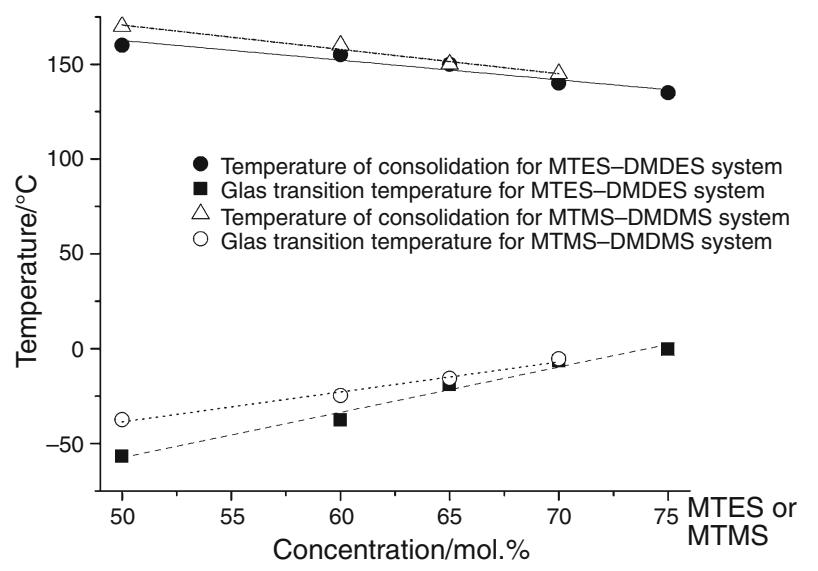

Fig. 6 Variation of the consolidation temperature $\left(T_{\mathrm{CON}}\right)$ and glass transition temperature $\left(T_{\mathrm{g}}\right)$ as a function of the amount of monosubstituted siloxane in MTES-DMDES and MTMS-DMDMS (30) systems 
investigate this trend, other non-hydrolytic groups such as phenyl and combinations of methoxy and ethoxy are being investigated. In addition, rheological studies are being carried out to better understand the process of crosslinking.

\section{Conclusions}

Melting gel behavior is observed in polysiloxane polymers that contain crosslinks between di-substituted and monosubstituted siloxanes. The reversible behavior of becoming rigid and then softening by cycling from room temperature to about $110{ }^{\circ} \mathrm{C}$ can be repeated many times. However, once the gel is heated to its consolidation temperature, it loses the ability to soften. The consolidation temperature increases with an increase in the number of non-hydrolytic groups. Gels with larger numbers of residual methyl groups have overall higher mass loss in thermal gravimetry. The mass loss occurs at the same temperature for all compositions in air, and at higher temperatures in nitrogen. Based on DSC, it appears that the consolidation temperature facilitates further crosslinking of the polysiloxane network. The increase in crosslinking results in an increase in the measured glass transition temperature, which is a reflection of a stiffer polymer.

\section{References}

1. Ungureanu S, Laurent G, Deleuze H, Babot O, Achard MF, Popa MI, Sanchez C, Backov R. Synthesis and characterization of new organically grafted silica foams. Colloids Surf A. 2010;360: 85-93.

2. Sanchez C, Julian B, Belleville P, Popall M. Application of hybrid organic-inorganic nanocomposites. J Mater Chem. 2005;15:3559-92.

3. Schmidt H. Organic modification of glass structure new glasses or new polymers? J Non-Cryst Solids. 1989;112:419-23.

4. Matsuda A, Sasaki T, Hasegawa K, Tatsumisago M, Minami T. Thermal softening behavior and application to transparent thick films of poly(benzylsilsesquioxane) particles prepared by sol-gel process. J Am Ceram Soc. 2001;84:775-80.

5. Masai H, Tokuda Y, Yoko T. Gel-melting method for preparation of organically modified siloxane low-melting glasses, J Mater Res. 2005;20:1234-41.

6. Kakiuchida H, Takahashi M, Tokuda Y, Masai H, Kuniyoshi M, Yoko T. Viscoelastic and structural properties of the phenylmodified polysiloxane system with a three-dimensional structure. J Phys Chem B. 2006;110:7321-7.

7. Kakiuchida H, Takahashi M, Tokuda Y, Masai H, Kuniyoshi M, Yoko T. Effects of organic groups on structure and viscoelastic properties of organic-inorganic polysiloxane. J Phys Chem B. 2007;111:982-8.

8. De Witte BM, Commers D, Uytterhoeven JB. Distribution of organic groups in the silica gels prepared from organoalkoxisilanes. J Non-Cryst Solids. 1996;202:35-41.

9. Park Y-W, Lee D-S, Kim S-H. Mechanical, surface and thermal properties of polyimide-polydimethylsiloxane nanocomposites fabricated by sol-gel process. J Appl Polymer Sci. 2004;91: 1774-83.

10. Yu S, Wong TKS, Pita K. Synthesis of organically modified mesoporous silica as a low dielectric constant intermetal dielectric. J Vac Sci Technol B. 2002;20:2036-42.

11. Yu S, Wong TKS, Hu X, Goh TK. Effect of processing temperature on the properties of sol-gel-derived mesoporous silica films. Thin Solid Films. 2004;462-463:306-10.

12. Yu S, Wong TKS, Hu X, Pita K. The effect of TEOS/MTES ratio on the structural and dielectric properties of porous silica films. J Electrochem Soc. 2003;150:F116-21.

13. Rao AV, Kulkarni M, Amalnerkar DP, Seth T. Superhydrophobic silica aerogels based on methyltrimethoxysilane. J Non-Cryst Solids. 2003;330:187-95.

14. Nadargi DY, Rao AV. Methyltriethoxysilane: New precursor for synthesizing silica aerogels. J Alloys Compd. 2009;467:397-404.

15. Latournerie J, Dempsey Ph, Hourlier-Bahlol D, Bonet J-P. Silicon oxycarbide glasses: Part 1. Thermochemical stability. J Am Ceram Soc. 2006;89:1485-91.

16. Parashar VK, Raman V, Bahl OP. Nitridation of sol-gel derived DMDES-TEOS copolymer gels to silicon carboxynitride. J Mater Sci Lett. 1997;16:1260-3.

17. Camino G, Lomakin SM, Lazzari M. Polydimethylsiloxane thermal degradation. Part 1. Kinetic aspects. Polymer. 2001;42: 2395-402.

18. Camino G, Lomakin SM, Legeard M. Polydimethylsiloxane thermal degradation. Part 2 . The degradation mechanism. Polymer. 2002;43:2011-5.

19. Yang J, Chen J, Song J. Studies of the surface wettability and hydrothermal stability of methyl-modified silica films by FT-IR and Raman spectra. Vib Spec. 2009;50:178-84.

20. West GD, Diamond GG, Dajda N, Smith ME, Lewis MH. Structural characterization of organosiloxane membranes, Br. Cer. Ceram Trans. 2003;102:93-8.

21. Standeker S, Novak Z, Knez Z. Removal of BTEX vapors from waste gas streams using silica aerogels of different hydrophobicity, J. Hazard Mater. 2009;165:1114-8.

22. Zhou W, Yang H, Guo X, Lu J. Thermal degradation behaviors of some branched and linear polysiloxanes. Polym Degrad Stab. 2006;91:1471-5.

23. Hohne GWH, Hemminger WF, Flammersheim H-J. Differential scanning calorimetry. Berlin: Springer; 2003.

24. Sankaraiah S, Lee JM, Kim JH, Choi SW. Preparation and characterization of surface-functionalized polysilsesquioxane hard spheres in aqueous medium. Macromolecules. 2008;41:6195-204.

25. Yang C-C, Wu P-Z, Chen W-C, Chen H-L. Low dielectric constant nanoporous poly(methyl silsesquioxane) using poly(styreneblock-2-vinylpyridine as template. Polymer. 2004;45:702-5961.

26. Ma S, Liu W, Su Q, Liu Y. Studies on thermal properties of epoxy resins modified with two kinds of silanes. J Macromol Sci B. $2010 ; 49: 43-56$.

27. Jitianu A, Doyle J, Amatucci G, Klein LC. Methyl-modified melting gels for hermetic barrier coatings. In: Proceedings MS\&T 2008 enabling surface coating systems: multifunctional coatings, Pittsburgh, PA, 2008, pp. 2171-2182.

28. Jitianu A, Amatucci G, Klein LC. Phenyl-substituted siloxane hybrid gels that soften below $140^{\circ} \mathrm{C}$. J Am Ceram Soc. 2008;92:36-40.

29. Jitianu A, Doyle J, Amatucci G, Klein LC. Methyl modified siloxane melting gels for hydrophobic films. J Sol-Gel Sci Technol. 2010;53:272-9.

30. Klein LC, Jitianu A. Organic-inorganic hybrid melting gels. J Sol-Gel Sci Technol. 2010;55:86-93. 